\title{
IRON ABSORPTION IN DOGS DURING ANEMIA DUE TO ACETYLPHENYLHYDRAZINE
}

\author{
By W. B. STEWART, PHILIP S. VASSAR, AND ROBERT S. STONE \\ (From the Department of Pathology, College of Physicians and Surgeons, Columbia University, \\ New York, N. Y.)
}

(Submitted for publication June 25, 1953; accepted August 3, 1953)

The mechanisms controlling the absorption of iron from the gastrointestinal tract have been under investigation for a number of years. It now appears that several factors can increase the absorption of iron above the small amounts normally absorbed. Early observations by Hahn, Bale, Lawrence, and Whipple (1) using radioactive isotopes of iron clearly demonstrated that the normal dog absorbed only small amounts of iron from the gastrointestinal tract, whereas the anemic iron deficient dog was capable of absorbing relatively large quantities of iron. This observation was extended to rats (2) and human subjects (3). It appeared, however, that in spite of adequate iron stores, excessive iron could be absorbed under certain circumstances. Patients with pernicious anemia, hemolytic anemia, and other anemias seemed to absorb more iron than normal when iron balance studies were done with the aid of radioactive isotopes (3). These types of anemia are generally associated with increased rather than decreased stores of iron. Furthermore, in several instances of prolonged anemia of various types which required multiple transfusion of blood over a number of years, there was deposited in the liver considerably more iron than had been administered by transfusion, suggesting an increase in the absorption of iron $(4,5)$. Studies in pigs deficient in pyridoxine (6) also suggested that the absorption of iron was increased, perhaps in this instance also because of the anemia which is regularly present.

Some of the above mentioned observations suggested to Granick (7) that anemia alone may have been responsible for the increased absorption of iron that was noted. Several objections to this idea are possible, however, since in all instances factors other than anemia have been present. These include abnormal gastric mucosa, deficiencies of iron and vitamins. It was, therefore, considered desirable to approach this problem by studying the influence of a chronic anemia on the absorption of iron in dogs in which these variables were controlled.

The anemia induced by acetylphenylhydrazine seemed an ideal method of conducting such a study. The only known action of this substance is to cause an increased destruction of erythrocytes. The anemia which it causes is of hemolytic type, little loss of essential building blocks for hemoglobin synthesis occurs, and the duration and severity of anemia can be readily controlled.

The experiments reported here indicate that under conditions of prolonged hemolytic anemia the dog absorbs excessive amounts of iron.

\section{METHODS}

All dogs were healthy adult mongrels, vaccinated against distemper, and freed of intestinal parasites by a commercial vermifuge. The diet consisted of dog meal supplemented by occasional cans of commercial canned dog meat.

The radioactive iron, a mixture of $\mathrm{Fe}^{5 s}$ and $\mathrm{Fe}^{\infty}$ as $\mathrm{FeCl}_{3}$ was obtained from the Atomic Energy Commission. Purity was insured by following the decay curve. Appropriate dilutions were analyzed for iron content, and a known aliquot as $\mathrm{FeCl}_{3}$ was administered by stomach tube to fasting dogs. Procedures for determining radioactivity were essentially those as reported by Yuile $e t$ al. (8).

Determinations of the level of iron in the plasma were done by the method of Kitzes, Elvehjem and Schuette (9).

Dogs were rendered anemic by the subcutaneous injection of acetylphenylhydrazine dissolved in distilled water. The dose varied from time to time depending upon the level of anemia desired, but was usually between 200 and $400 \mathrm{mg}$. every other day. Care was taken to minimize hemoglobinemia in order to avoid loss of iron by renal excretion of hemoglobin.

After various periods of anemia, the dogs were given a single dose of a known amount of radioactive iron and the administration of acetylphenylhydrazine was stopped. The appearance of radioactivity in the erythrocytes was determined at weekly intervals for three weeks by which time the hematocrit readings had returned to normal. As controls most of the dogs were later given another dose of radioactive iron to determine absorption under normal conditions. 
Calculation of absorption was based upon an estimation of the blood volume and the concentration of radioactivity in the packed erythrocytes. The blood volume was assumed to be 8 per cent of the body weight. This value was multiplied by the venous hematocrit to give the red cell volume. The product of the red cell volume and the concentration of radioactivity in the packed red cells yielded the total circulating radioactivity. From this the per cent of utilization was computed.

$$
\% \text { utilized }=\frac{\text { body weight } \times 0.08 \times \text { hematocrit }}{\times \text { radioactivity per } \mathrm{ml} . \mathrm{RBC} \times 100}
$$

As will be seen, the difference between anemic phenylhydrazine treated and control animals was so great that the relatively small errors involved in this calculation were negligible. The amount of radioactive iron utilized for hemoglobin synthesis was assumed to be a close estimate of the amount absorbed.

\section{RESULTS}

The results are summarized in the table. From the figures in column 3 it will be seen that all dogs had hematocrit values in the normal range at the beginning of the experiments. Hematocrit readings taken at the time the radioactive iron was given are listed in column 4 . In general these values are representative of the degree of anemia induced during acetylphenylhydrazine administration, but moderate fluctuations were unavoidable. Levels of iron in the plasma are given in columns 5 and 6 . All values fell within the normal range at the beginning of the experiments. Following administration of acetylphenylhydrazine the levels of iron in the plasma were in general higher than the baseline values. Dog 393 had a low plasma iron level after two weeks of acetylphenylhydrazine. We have noted in other animals that there is frequently a period, early in the course of phenylhydrazine anemia during which the level of plasma iron may be temporarily depressed. Dog 400 after prolonged phlebotomy had a low concentration of iron in the plasma. This is the expected finding.

The size in milligrams of the labelled dose of iron is given in column 7 . In most of these experiments about $5 \mathrm{mg}$. were given. When larger or smaller amounts were given to anemic dogs, the controls were done with the same dose. Dog 400 received a relatively large amount, $16.6 \mathrm{mg}$., and dog 398 received a very small amount, $0.47 \mathrm{mg}$., in one experiment.

The amount of radioactivity found in the erythrocytes three weeks later is given in the last col- umn. The figures are computed as per cent of the administered radioactivity and were calculated as described above under Methods. The figure in parentheses after dog 400 indicates the per cent of the radioactivity administered which was found by determining the amount of radioactivity removed by prolonged bleeding. This procedure withdrew from storage all the iron available for hemoglobin synthesis. This figure of 10 per cent was in good agreement with the 8.8 per cent previously estimated to be in the peripheral blood. This agreement indicated that all or nearly all of the iron absorbed from the gastrointestinal tract was utilized for hemoglobin synthesis rather than being deposited in the iron stores.

It is apparent from the figures in this column that under the experimental conditions the absorption of iron from the gastrointestinal tract was increased several fold above that of the controls. Dog 400 absorbed 10 per cent of $16.6 \mathrm{mg}$. of $\mathrm{FeCl}_{3}$ after four months of anemia induced by acetylphenylhydrazine. After the dog had been rendered iron deficient by prolonged bleeding, he absorbed 13 per cent of a dose of the same size. The dog was allowed to regenerate his hemoglobin with the aid of an adequate iron intake by mouth and $0.3 \mathrm{Gm}$. of ordinary iron administered intravenously. After this he absorbed only 2.9 per cent of a $16.4 \mathrm{mg}$. dose of $\mathrm{FeCl}_{3}$. Dog 398 absorbed 13 per cent of $0.47 \mathrm{mg}$. after three months of acetylphenylhydrazine and only 1.8 per cent of a test dose of the same size when the hematocrit had returned to normal. In the remaining experiments a dose of $5 \mathrm{mg}$. of $\mathrm{FeCl}_{3}$ was given. After 34 days of anemia, dog 403 absorbed 38 per cent, a figure clearly above the normal absorption of 2 to 6 per cent. Two dogs were given a test dose of radioactive ferric chloride after only two weeks of anemia. Dog 393 absorbed only 4.2 per cent, whereas dog 392 absorbed 13 per cent. It seems that two weeks of anemia may be effective in some animals, but not in others.

\section{DISCUSSION}

Phenylhydrazine anemia in these dogs consistently increased gastrointestinal iron absorption if the animals were anemic for longer than 14 days. The increased iron absorption was not due to lack of iron in the body because: 1) Care was taken to prevent excessive iron loss from hemoglobinuria; 
2) iron lost in the bile was probably insignificant in amount (10); and 3 ) the dogs recovered promptly from the anemia when phenylhydrazine administration was stopped. It seems reasonable, therefore, to attribute the excessive iron absorption to the anemia.

The explanation of this increased absorption of iron is obscure. Granick (7) has suggested that anoxia produced by anemia alters the redox level of the mucosal cells. Such a change, affecting the hypothetical ferritin mechanism of the cells, would allow increased amounts of iron to enter the body. This suggestion seems reasonable, but there is as yet little direct evidence to support it. Moreover, factors other than anemia can cause increased iron absorption. For example, the dietary siderosis produced by Hegsted, Finch, and Kinney (11) is not known to be associated with anemia. Somewhat similar diets have also caused increased absorption of iron in the face of a normal level of hemoglobin (12). Whether the intestinal mucosa is anoxic when rats are fed such deficient diets is not known, however.

Increases in mucosal iron have been shown to suppress the absorption of iron in anemic iron deficient dogs (13). There also is evidence indicating that in states of iron excess induced by diet the rate of absorption of iron is decreased (12). During the hemolytic process induced by acetylphenylhydrazine one would expect the mucosal and storage iron to be higher than normal, thus tending to decrease the absorption, rather than allowing increased absorption, but such is not the case. It would seem reasonable then to suspect that an ane- mia of long duration can overcome the "mucosal block" thought to be induced by the presence of iron in the mucosal cells, even though acute anemia does not do so (14).

The increased absorption of iron in these dogs took place when the concentration of iron in the plasma was elevated. This observation supports earlier work $(3,15)$ discounting the influence of plasma iron levels upon the absorption of iron from the gastrointestinal tract.

A difference between species seems to exist with respect to the effect of acetylphenylhydrazine upon the absorption of a single dose of iron from the gastrointestinal tract. Rats fed acetylphenylhydrazine for one month absorbed less of a single dose of an iron salt than control rats (16). The authors stated, however, that long term experiments indicated an increased absorption of iron in rats fed acetylphenylhydrazine.

Utilization for hemoglobin synthesis of orally fed iron as a measure of absorption from the intestinal tract has been criticized (3). Such criticism does not apply to these experiments since falsely low rather than falsely high values for iron absorption would have been obtained if a large fraction of recently absorbed iron had been diverted from the hemoglobin to stores. Falsely high values would have resulted only if labelled iron from stores had been incorporated into the red cell mass. This could have happened only in dogs 393 and 392 in our series, since none of the other dogs had received any radioactive iron prior to being placed on acetylphenylhydrazine. Furthermore, it has been recently demonstrated that only a small frac-

TABLE I

The absorption of iron during hemolytic anemia in dogs

\begin{tabular}{|c|c|c|c|c|c|c|c|c|}
\hline \multirow[b]{2}{*}{ Dog } & \multirow[b]{2}{*}{ Conditions } & \multicolumn{2}{|c|}{ Hematocrit } & \multicolumn{2}{|c|}{ Plasma iron } & \multirow{2}{*}{$\begin{array}{l}\text { Dose of radio- } \\
\text { active ferric } \\
\text { chloride }\end{array}$} & \multirow[b]{2}{*}{ Utilization } & \\
\hline & & Normal & Anemic & Normal & Anemic & & & \\
\hline $\begin{array}{l}400 \\
400 \\
400 \\
398 \\
398 \\
398 \\
398 \\
403 \\
401 \\
393 \\
393 \\
392\end{array}$ & $\begin{array}{l}\text { APH* } 4 \text { months } \\
\text { iron deficient } \\
\text { normal } \\
\text { APH } 3 \text { months } \\
\text { normal } \\
\text { APH } 3 \text { months } \\
\text { normal } \\
\text { APH } 34 \text { days } \\
\text { APH } 3 \text { weeks } \\
\text { APH } 2 \text { weeks } \\
\text { normal } \\
\text { APH } 2 \text { weeks }\end{array}$ & $\begin{array}{c}\% \\
46.7 \\
50.0 \\
48.1 \\
52.4 \\
48.1 \\
48.0 \\
50.0 \\
60.0 \\
53.9 \\
57.1 \\
43.3 \\
44.1\end{array}$ & $\begin{array}{c}\% \\
32.4 \\
37.8 \\
\overline{34.0} \\
\overline{27.6} \\
\overline{30.2} \\
34.0 \\
30.0 \\
\overline{23.0}\end{array}$ & $\begin{array}{c}r / 100 \mathrm{ml} . \\
103 \\
103 \\
198 \\
104 \\
= \\
= \\
\overline{136} \\
159 \\
141 \\
\overline{175}\end{array}$ & $\begin{array}{c}\gamma / 100 \mathrm{ml} . \\
194 \\
60 \\
\frac{165}{-} \\
248 \\
\overline{210} \\
161 \\
\frac{70}{225}\end{array}$ & $\begin{array}{c}\text { mg. } \\
16.6 \\
16.6 \\
16.4 \\
.47 \\
.47 \\
5.42 \\
5.42 \\
5.01 \\
5.01 \\
5.01 \\
5.01 \\
5.01\end{array}$ & $\begin{array}{c}\text { \% of dose } \\
8.8 \\
13 \\
2.9 \\
13 \\
1.8 \\
17 \\
2.6 \\
38 \\
25 \\
4.2 \\
1.8 \\
13\end{array}$ & $(10) \dagger$ \\
\hline
\end{tabular}

* Indicates the subcutaneous injection of acetylphenylhydrazine.

t Based upon measurement of radioactive iron removed by repeated and prolonged phlebotomy. 
tion of stored iron is used to replenish the iron of hemoglobin during recovery from anemia caused by acetylphenylhydrazine (17).

The fact that absorption of iron from the gastrointestinal tract is increased during a hemolytic anemia has certain clinical implications. The use of medicinal iron in anemias not caused by a deficiency of iron is possibly dangerous. Indeed, excessive iron deposition in the viscera of a patient with hereditary sypherocytosis has occurred (18). This patient was given medicinal iron for many years as a placebo. The effects of such excessive deposits of iron are not yet clear, but it would seem wise to avoid excessive iron deposition if possible.

\section{SUMMARY}

Dogs were given subcutaneous injections of acetylphenylhydrazine to make them anemic. After various periods of anemia a test dose of radioactive iron was given by stomach tube.

All animals which had been anemic at least three weeks absorbed more iron from the gastrointestinal tract than controls. One of two dogs which were anemic for only two weeks absorbed more than a normal amount of iron.

It was concluded that hemolytic anemia caused increased absorption of iron in dogs.

\section{REFERENCES}

1. Hahn, P. F., Bale, W, F., Lawrence, E. O., and Whipple, G. H., Radioactive iron and its metabolism in anemia. Its absorption, transportation, and utilization. J. Exper. Med., 1939, 69, 739.

2. Copp, D. H., and Greenberg, D. M., A tracer study of iron metabolism with radioactive iron. I. Methods: absorption and excretion of iron. J. Biol. Chem., 1946, 164, 377.

3. Dubach, R., Callender, S. T. E., and Moore, C. V., Studies in iron transportation and metabolism. VI. Absorption of radioactive iron in patients with fever and with anemias of varied etiology. Blood, $1948,3,526$.

4. Muirhead, E. E., Crass, G., Jones, F., and Hill, J. M., Iron overload (hemosiderosis) aggravated by blood transfusions. Arch. Int. Med., 1949, 83, 477.
5. Wyatt, J. P., Mighton, H. K., and Moragues, V., Transfusional siderosis. Am. J. Path., 1950, 26, 883.

6. Cartwright, G. E., Wintrobe, M. M., and Humphreys, S., Studies on anemia in swine due to pyridoxine deficiency, together with data on phenylhydrazine anemia. J. Biol. Chem., 1944, 153, 171.

7. Granick, S., Iron metabolism and hemochromatosis. Bull. New York Acad. Med., 1949, 25, 403.

8. Yuile, C. L., Bly, C. G., Stewart, W. B., Izzo, A. J., Wells, J. C., and Whipple, G. H., Plasma and red cell radioiron following intravenous injection. Turpentine abscesses in normal and anemic dogs. J. Exper. Med., 1949, 90, 273.

9. Kitzes, G., Elvehjem, C. A., and Schuette, H. A., The determination of blood plasma iron. J. Biol. Chem., 1944, 155, 653.

10. Hawkins, W. B., and Hahn, P. F., Biliary excretion of radioactive iron and total iron as influenced by red cell destruction. J. Exper Med., 1944, 80, 31.

11. Hegsted, D. M., Finch, C. A., and Kinney, T. D., The influence of diet on iron absorption. II. The interrelation of iron and phosphorus. J. Exper. Med., 1949, 90, 147.

12. Stewart, W. B., and Shils, M. E., Unpublished observations.

13. Stewart, W. B., Yuile, C. L., Claiborne, H. A., Snowman, R. T., and Whipple, G. H., Radioiron absorption in anemic dogs. Fluctuations in the mucosal block and evidence for a gradient of absorption in the gastrointestinal tract. J. Exper. Med., 1950, $92,375$.

14. Hahn, P. F., Bale, W. F., Ross, J. F., Balfour, W. M., and Whipple, G. H., Radioactive iron absorption by gastro-intestinal tract. Influence of anemia, anoxia, and antecedent feeding. Distribution in growing dogs. J. Exper. Med., 1943, 78, 169.

15. Yuile, C. L., Hayden, J. W., Bush, J. A., Tesluk, H., and Stewart, W. B., Plasma iron and saturation of plasma iron-binding protein in dogs as related to the gastrointestinal absorption of radioiron. J. Exper. Med., 1950, 92, 367.

16. Saylor, L., and Finch, C. A., Determination of iron absorption using two isotopes of iron. Am. J. Physiol., 1953, 172, 372.

17. West, H. D., Hahn, P. F., Clark, W. F., and Chappelle, E. W., Labeled iron stores in study of iron liberated during red cell destruction by acetylphenylhydrazine. Am. J. Physiol., 1952, 169, 194.

18. Wallerstein, R. O., and Robbins, S. L., Hemochromatosis after prolonged oral iron therapy in a patient with chronic hemolytic anemia. Am. J. Med., 1953, 14, 256. 